\title{
Differentiating aortic fibrosarcoma from acute intramural hematoma
}

\author{
Yader Sandoval, MD, ${ }^{\mathrm{a}}$ Joseph Van Camp, MD, ${ }^{\mathrm{b}}$ Stuart Cameron, MD,${ }^{\mathrm{c}}$ Charles A. Herzog, MD, ${ }^{\mathrm{a}}$ and

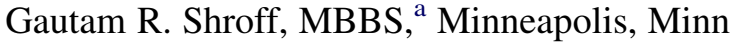

An 86-year-old woman with a medical history of hypertension was transferred to the Hennepin County Medical Center for severe substernal chest pain radiating to her back, associated with coughing. Physical examination revealed normal heart sounds with irregular heart rate, symmetric pulses, and intact neurologic examination. Electrocardiogram on admission showed atrial fibrillation. Chest computed tomography (CT) with contrast obtained before her transfer demonstrated soft tissue surrounding her ascending aorta, which was diagnosed as an aortic intramural hematoma (Figure 1) and a small pericardial effusion. An aortic dissection flap was not observed. Transthoracic echocardiography before emergency surgical exploration showed a soft tissue collection posterior to the ascending aorta without a dissection flap and a small pericardial effusion. On surgical exploration, a large white mass completely surrounding the distal ascending aorta and compressing the superior vena cava was observed. Biopsies from this mass were obtained showing a monomorphic spindle cell sarcoma (Figure 2). Immunostains for a variety of markers were negative, including wide spectrum cytokeratin, cytokeratin $5 / 6$, Wilms' tumor protein 1 , Transducinlike enhancer of split 1, CD34, actin, desmin, and S-100. The morphology and immunohistochemistry were consistent with a high-grade adult-type fibrosarcoma. No other surgical intervention was performed. The patient elected to have her care at a different institution, and therefore no follow-up data are available. On the basis of the above stains, the tumor could be aortic or cardiac in origin.

\section{DISCUSSION}

Soft tissue sarcoma of the heart or the large vessels is a rare clinical entity, accounting for only $1 \%$ of all sarcomas. ${ }^{1}$ A recent series by Bahrami and Folpe ${ }^{2}$ at Mayo Clinic concluded that true fibrosarcoma is rare, accounting for less than $1 \%$ of approximately 10,000 adult soft tissue sarcomas seen at Mayo

\footnotetext{
From the Division of Cardiology, ${ }^{a}$ Department of Medicine, and Departments of Cardiovascular Surgery ${ }^{\mathrm{b}}$ and Pathology, ${ }^{\mathrm{c}}$ Hennepin County Medical Center, Minneapolis, Minn.

Disclosures: Authors have nothing to disclose with regard to commercial support. Received for publication Aug 30, 2011; accepted for publication Oct 12, 2011; available ahead of print Nov 7, 2011.

Address for reprints: Yader Sandoval, MD, Department of Medicine, Hennepin County Medical Center, 701 Park Avenue, Minneapolis, MN 55415 (E-mail: yadersandoval@gmail.com).

J Thorac Cardiovasc Surg 2012;143:e7-8

$0022-5223 / \$ 36.00$

Copyright (C) 2012 by The American Association for Thoracic Surgery

doi:10.1016/j.jtcvs.2011.10.016
}

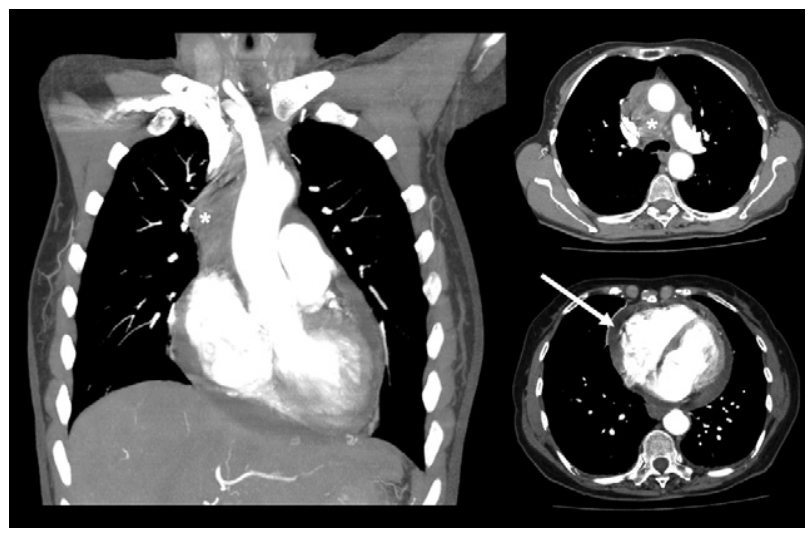

FIGURE 1. CT with contrast shows the tumor (asterisk) in both long-axis and transverse views. The pericardial effusion is also evident in the transverse view (arrow).

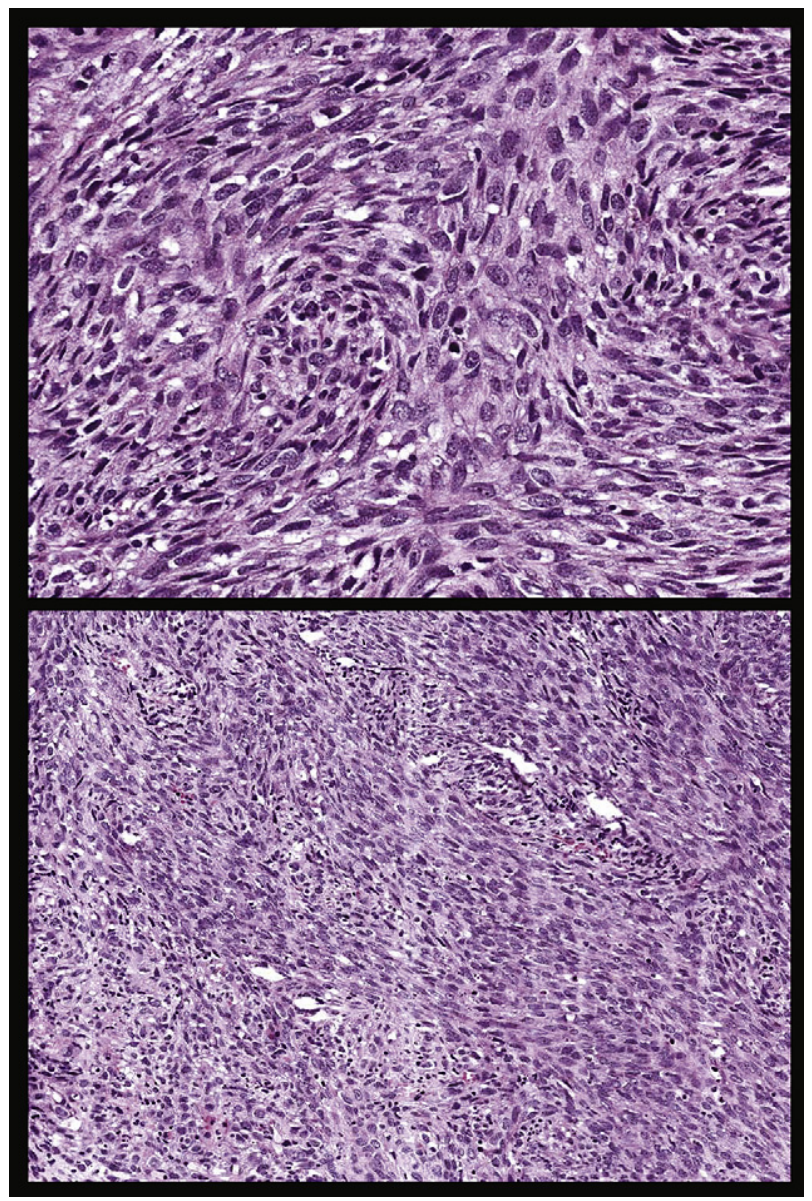

FIGURE 2. Histopathology. Biopsy from mass was obtained, showing a monomorphic spindle cell sarcoma. 
Clinic. The diagnosis of fibrosarcoma is reserved for those tumors in which no specific form of cellular differentiation is identified by light or electron microscopy or by immunohistochemistry. The prognosis of patients with soft tissue sarcoma of the heart and the great vessels is dismal, because many patients present with locally advanced or metastatic disease at the time of initial diagnosis. ${ }^{1}$

This case highlights important teaching points. Fibrosarcoma surrounding the ascending aorta may mimic aortic dissection, ${ }^{3}$ and cardiovascular imaging is an important tool in establishing a noninvasive diagnosis. Aortic dissection and intramural hematoma are more common compared with other primary aortic pathologies. Aortic intramural hematoma is characterized primarily by aortic wall hematoma without a demonstrable intimal flap or penetrating ulceration and can be defined with CT as a localized, crescentric, high attenuation area long the aortic wall on non-contrast $\mathrm{CT}$ and relatively low attenuation area without enhancement on contrast-enhanced $\mathrm{CT}^{4}{ }^{4}$ In retrospect, clues for the tumor in our patient were the presence of subtle enhancement in the mass, irregular margins, and possibly violation of tissue planes.

\section{CONCLUSIONS}

Both transthoracic and transesophageal echocardiography are limited in their ability to allow characterization of soft tissue masses. If a tumor is suspected, magnetic resonance can be helpful to define tissue characteristics and can be considered, especially in non-emergency settings. ${ }^{5}$ A high index of clinical suspicion needs to be maintained for conditions such as aortic and cardiac tumors, which are rare in clinical practice.

\section{References}

1. Mayer F, Herman H, Rudert M, et al. Primary malignant sarcomas of the heart and great vessels in adult patients-a single-center experience. Oncologist. 2007;12: 1134-42.

2. Bahrami A, Folpe AL. Adult-type fibrosarcoma: a reevaluation of 163 putative cases at a single institution over a 48-year period. Am J Surg Pathol. 2010;34: 1504-13.

3. Borislow DS, Floyd WL, Sane DC. Primary aortic sarcoma mimicking aortic dissection. Am J Cardiol. 1989;1:549-51.

4. Kaji S, Nishigami K, Akasaka T, et al. Prediction of progression or regression of type A aortic intramural hematoma by computed tomography. Circulation. 1999. II-281-6.

5. Sparrow PJ, Kurian JB, Jones TR, Sivananthan MU. MR imaging of cardiac tumors. Radiographics. 2005;25:1255-76. 